\title{
De la resistencia urbana al urbanismo ciudadano. Sujetos y estrategias patrimoniales en Concepción Metropolitano, Chile ${ }^{1}$
}

\author{
Leonel Pérez ${ }^{2}$ y Christian Matus ${ }^{3}$
}

\begin{abstract}
RESUMEN
Desde 2010 se moviliza en Concepción metropolitano una significativa revaloración del patrimonio urbano como herramienta de construcción de espacio público y rescate de identidades locales, cuyo ejemplo más patente es la declaratoria como Monumento Nacional de la Fábrica Bellavista Tomé en 2016. Se aborda el concepto de patrimonio y sus tensiones, planteando nexos con la participación ciudadana, desarrollando una mirada analítica de las intervenciones desarrolladas por tres plataformas ciudadanas, relacionadas con el patrimonio en Concepción, Tomé, Talcahuano, en los últimos cinco años. Un análisis descriptivo de sus prácticas de apropiación y activación patrimonial permite explicar la lógica de acción de dichos colectivos y estudiar sus acciones de gestión patrimonial como expresiones de un urbanismo participativo, revelando el aporte ciudadano de nuevas prácticas de uso y gestión que van desde una visión tradicional del patrimonio hasta una noción que plantea su revaloración a partir del ejercicio de un derecho al patrimonio.
\end{abstract}

Palabras clave: Patrimonio urbano, ciudadanía, sustentabilidad, derecho al patrimonio.

\begin{abstract}
From 2010 is mobilized in Concepción a significant enhancement of urban heritage as a tool for building public space and rescue of local identities, whose most striking example is the declaration of National Monument Bellavista Tomé Factory in 2016. It addresses the concept of heritage and tensions, raising ties with citizen participation, developing an analytical view of interventions developed by three citizens, related to heritage in Concepción, Tomé, Talcahuano, in the last five years. A descriptive analysis of their practices of appropriation and property activation helps explain the logic of action of these groups and study their actions wealth management as expressions of a participatory urbanism, revealing citizen input of new practices of use and management ranging from a vision traditional heritage to a notion that arises from the revaluation exercise of a right to heritage.
\end{abstract}

Keywords: Urban heritage, citizenship, sustainability, right to heritage.

Nuestros agradecimientos al Centro CONICYT/FONDAP 15110020, Centro de Desarrollo Urbano Sustentable (CEDEUS) y al Proyecto CONICYT-PIA SOC 1403. Artículo recibido el 30 de julio de 2015, aceptado el 23 de noviembre de 2015 y corregido el 23 de septiembre de 2016.

Investigador CEDEUS / Departamento de Urbanismo, Universidad de Concepción (Chile).E-mail: leperez@udec.cl

Investigador Postdoctoral CEDEUS / Universidad de Concepción (Chile). E-mail: christianmatus@udec.cl 
Una mirada actual sobre el campo de "lo patrimonial" constata que este deviene en un concepto nómade que requiere ser contextualizado e interrogado para definir con claridad cómo y desde donde se habla del patrimonio, dado las múltiples definiciones y apropiaciones que actualmente de él hacen, especialistas, ciudadanos, privados y autoridades públicas (Déom \& Thiffault, 2013: 62). Como ya planteara Choay (2007) el culto que se rinde hoy al patrimonio merece más que una aprobación unánime, un cuestionamiento en términos de develar sus tensiones y contradicciones. En particular, si abordamos la relación entre patrimonio y ciudadanía debemos comprender que las acciones de puesta en valor patrimonial que desarrollan grupos ciudadanos implican un acto de selección realizado por grupo -más o menos representativo- del "sentir de la comunidad", sobre un conjunto de elementos materiales e inmateriales, que forman parte de un universo cultural propio del barrio como espacio percibido (Lefebvre, 2014).

En ese marco es pertinente analizar los procesos de "patrimonialización" que desarrollan las comunidades de modo de entender cómo y qué es lo que seleccionan como parte de su patrimonio. En Chile se ha comenzado a indagar cómo las comunidades barriales se apropian de la identidad y el patrimonio como herramienta de defensa territorial ante el impacto de los procesos de metropolización, como demuestran los casos de la movilización del Barrio Bellavista contra el proyecto de Costanera Norte (Sagaris, 2014), y más recientemente el trabajo de Paulsen (2014) sobre movimiento de defensa barrial desarrollado por vecinos del Barrio Yungay para defender su modo de vida del impacto del desarrollo inmobiliario en el entorno del centro histórico de Santiago . No obstante, no existe un abordaje de cómo estos procesos se están desarrollando en otras áreas urbanas a escala regional. Este trabajo aporta una mirada reflexiva sobre los procesos de puesta en valor del patrimonio por parte de diferentes comunidades que forman parte del Concepción Metropolitano ${ }^{4}$. A partir de una aproximación cualitativa a la experiencia de tres agrupaciones patrimoniales interesa dar cuenta de ¿cómo y desde donde construyen patrimonio las ciudadanías del Concepción Metropolitano?. En primer lugar, resulta fundamental comprender el rol que juega en la construcción de ciudadanía en un territorio costero configurado históricamente en base a la producción industrial textil, siderúrgica y carbonífera. Por otra parte, la pregunta es central para entender también el sentido que asume el patrimonio como herramienta de reflexión colectiva sobre el pasado, presente y futuro en territorios que encuentran sometidos a fuertes procesos de transformación en los últimos veinte años, procesos de conurbación de comunas y extensión urbana (Aliste, Almendras \& Contreras, 2012), que han modificado los modos de vida de localidades cuya identidad se construyó en función de un pasado productivo de carácter industrial y que hoy parecen percibir la ausencia de un proyecto de futuro que los haga partícipes. En ese marco es relevante retomar la mirada de Hiernaux (2007) sobre la fuerte presencia de un "imaginario de la des-ciudadización", de la pérdida de la ciudad tradicional, representación sobre la extinción del sentido de urbanidad y del carácter urbanita de la ciudad, que motiva a que las comunidades de base se movilicen por la defensa de una identidad que ven amenazada por los procesos de metropolización.

Planteamos como supuesto de investigación que en Concepción, producto del impacto del terremoto y tsunamis del 27 de febrero de 2010 se visibiliza un importante ejercicio de revalora-

Elegimos hablar de "Concepción Metropolitano" para referirnos al Área Metropolitana de Concepción (AMC) territorio que comprende diez comunas: Concepción, Coronel, Chiguayante, Lota, Penco, San Pedro de la Paz, Talcahuano, Hualpén, más Hualqui y Santa Juana. Comprende aproximadamente el $50 \%$ de la Provincia de Concepción y el 47\% de la población regional con 871.231 habitantes al último censo válido (INE, 2002). 
ción del patrimonio urbano como herramienta de construcción de espacio público y rescate de identidades locales por parte de ciudadanos organizados de sus principales ciudades, los que en ausencia de una política local de gestión patrimonial se constituyen en sí mismos como "sujetos patrimoniales" (Carrión, 2010), entendiendo éste como el proceso de empoderamiento de los actores locales, que se hacen cargo de gestionar y activar su patrimonio local.

Al igual que el fenómeno que visibilizan otros estudios asociados al patrimonio y la identidad en áreas metropolitanas como la AMS de Santiago (GORE-SUBDERE, 2010), los actores que protagonizan la defensa y gestión ciudadana del patrimonio son agrupaciones compuestas tanto por líderes vecinales de comunidades locales, como por profesionales asociados al urbanismo, la arquitectura y la historia, cuya apropiación del patrimonio en el contexto del auge y predominio del uso de nuevas plataformas de comunicación (Tironi, 2014: 55; Castells, 2003) y formas organizacionales, genera nuevas prácticas de gestión patrimonial, aprendizajes sociales, que es necesario procesar y analizar desde el mundo académico.

Se aborda en primer lugar, una revisión acerca del concepto de patrimonio y sus tensiones en el contexto de los procesos de globalización y desarrollo urbano, planteando su nexo con la participación y las nuevas propuestas que plantea el urbanismo participativo, para el uso y gestión del patrimonio. Posteriormente, se ofrece, a partir de la metodología de estudio de casos, un análisis de las prácticas de uso y activación patrimonial desarrolladas por tres plataformas urbanas, colectivos y agrupaciones ciudadanas que desarrollan acciones relacionadas con el patrimonio en las ciudades de Concepción, Tomé y Talcahuano. Se desarrolla un análisis descriptivo de la lógica de acción de los colectivos, analizando sus acciones de gestión patrimonial como expresiones de un urbanismo ciudadano, entregando una primera caracterización del aporte ciudadano a la activación patrimonial en Concepción Metropolitano, sistematizando el ejercicio de nuevas prácticas de uso y gestión que van desde una visión tradicional del patrimonio hasta una noción que plantea su revitalización a partir del ejercicio de un derecho al patrimonio en el contexto más amplio de la revitalización de los espacios públicos de la ciudad.

\section{Del concepto tradicional de patrimonio al patrimonio como recurso de la cultura}

El patrimonio cambia en su forma de ser concebido, desde una mirada tradicional asociada a la conservación y la monumentalidad a un enfoque socio-cultural que explora en sus usos y significados colectivos. Como plantea Choay (2007) es la difusión de los valores y las nuevas referencias respecto a "lo patrimonial" del mundo occidental, que se expanden a partir de los procesos de globalización cultural y económica, la que aporta a difundir una mirada más amplia y ecuménica sobre el patrimonio. Con los procesos de "mundialización" (Ortiz, 2004) el patrimonio pasa a hacer un fenómeno multi-escalar del cual no sólo se hacen cargo los especialistas, sino que las comunidades locales en donde "lo patrimonial" se emplaza; las autoridades políticas tanto locales, regionales como nacionales ${ }^{5}$, que ven el patrimonio un atributo que fortalece la identidad; y una comunidad translocal que a partir de convenciones reivindica más allá de las fronteras

Es así como se consolida la noción de "Patrimonio cultural" promovida por los Estados y gobiernos cuyo ejemplo más patente es la creación del "día del patrimonio" en Francia, y que a partir de 2000, en el gobierno de Ricardo Lagos, se implementa en Chile. 
nacionales, su defensa y apropiación configurando un marco de referencia normativo para la gestión del patrimonio global.

Siguiendo una perspectiva constructivista, el patrimonio puede ser definido como el conjunto de atributos o bienes materiales e inmateriales, que hereda una comunidad a otra en el tiempo, en donde siempre hay un acto de selección y toma de decisión de lo que se integra y lo que se excluye como herencia, acto de selección que es siempre en un tiempo presente. En ese marco, siguiendo a García Canclini, la puesta en valor patrimonial debe ser indagada en sus tensiones, abordando los procesos sociales fluctuantes y contradictorios que forman parte del "campo simbólico" de lo patrimonial. En ese marco este constituye "un proceso social, que como el otro capital, se acumula, se reconvierte, produce rendimientos y es apropiado en forma desigual por diversos actores" (1999: 182)

Para Harvey (2001) el patrimonio como proceso social constituye un proceso histórico de largo aliento, que se intensifica con la modernidad. A medida que esta se desarrolla, la tecnología permite un enorme incremento en la capacidad de almacenar, clasificar, interpretar y presentar este depósito más amplio de tiempo. Las transformaciones implícitas en la modernidad simplemente se reflejan en un aumento e intensificación, del reciclaje, la profundidad y alcance de la actividad de patrimonio. Los cambios tecnológicos, por lo tanto, llevan a aumentar la capacidad de almacenar, articular y "producir patrimonio", así como las cambiantes prácticas de ocio permiten un mayor margen para interpretar y "hacer" patrimonio construyendo "narrativas patrimoniales".

El hecho de que el patrimonio sea una construcción plantea el reto de describir y analizar cómo se desarrollan los procesos de "selección patrimonial", determinando que motivaciones llevan a las comunidades a elegir determinados espacios, lugares, oficios e incluso modos de vida como patrimoniales dejando a otros elementos de la cultura fuera de dicho proceso de puesta en valor. Esto lleva a Prats (2005: 18-20) a plantear que la "patrimonialización" se constituye por dos componentes o construcciones sociales distintas: a) "La sacralización de la externalidad cultural", que plantea el mecanismo universal mediante el cual toda sociedad define un ideal de mundo y la existencia de todo elemento cultural que no cabe en él o lo contradice pasa a formar un "más allá" que desborda la condición humana socialmente definida; y b) "La puesta en valor o activación patrimonial", haciendo la diferencia entre poner en valor (o valorar simplemente) determinados elementos patrimoniales, y activarlos o actuar sobre ellos de alguna forma.

En relación a la puesta en valor se produce un primer proceso de negociación en la medida que ya en la sociedad existe una previa puesta en valor jerarquizada. En ese marco la "activación patrimonial" tiene que ver con los "discursos" o "reglas gramaticales" propias del patrimonio, que implican: la selección de elementos integrantes de la activación; la ordenación de estos elementos (equivalente a la construcción de las frases del discurso); y la interpretación, que restringe la polisemia de cada elemento-palabra mediante recursos diversos (texto, iluminación, ubicación). En torno a las activaciones patrimoniales se plantearía un segundo plano de negociación más complejo en que los actores principales son los actores políticos y la sociedad. El objetivo, con frecuencia implícito, de la negociación es alcanzar el mayor grado de consenso posible, de manera que el discurso subyacente en la activación aparezca legitimado y conforme a la realidad socialmente percibida. 


\section{Tensiones de la "patrimonialización" y efectos urbanos de su puesta en valor}

Una de las tensiones inherentes al contexto actual de desarrollo del concepto tienen que ver con el proceso mismo de puesta en valor del patrimonio urbano o "patrimonialización" de antiguos espacios urbanos como centros históricos y barrios tradicionales, cuya puesta en valor constituye una herramienta que forma parte del modelo de competencia entre ciudades. Al respecto diversos autores han abordado los efectos de la "patrimonialización" en las ciudades latinoamericanas. Scarpaci (2005) en un estudio comparativo sobre el turismo patrimonial en nueve ciudades latinoamericanas, plantea que la tendencia a la "patrimonialización" del centro histórico de las ciudades crea fuertes tensiones entre la preservación de identidades nacionales a través de la protección de la arquitectura colonial y la erosión de estas identidades productos de las presiones del consumo. Por su parte, Sosa (2012), a partir de un estudio sobre el casco histórico de Buenos Aires, aborda las tensiones que atraviesa el patrimonio dado su doble rol. Por un lado, como recurso cultural es una forma de conocimiento que implica el doble proceso de legitimación de una historia (la historia oficial) y de una construcción de una identidad (nacional o local). Por otro, como recurso económico permite configurar plusvalía dentro del esquema de marketing territorial que determina que las ciudades globales compitan por la localización de flujos sociales, económicos y financieros. Para Carrión (2005a; 2005b) en su estudio sobre los centros históricos latinoamericanos, el "centro histórico patrimonial" deviene en "espacio de deseo" por parte de diferentes actores que se apropian de su valor y significado de distinción en un contexto de fragmentación de la ciudad. Según el autor, los procesos de puesta en valor del centro urbano determinan un cambio en el abordaje cultural de espacios urbanos que se encontraban en decadencia, y que son "re-descubiertos" en su valoración social, lo que genera un aumento de la demanda simbólica y material de dichos espacios en tanto "bienes patrimonializados". Esta demanda simbólica es claramente leída por desarrolladores urbanos como empresas inmobiliarias que tienden a apropiarse de la estética o imagen patrimonial para la ventas de sus nuevos proyectos, o desarrollar nuevos rubros de " rehabilitación patrimonial".

En Chile, Hidalgo y Janoschka (2014), han demostrado como las clases populares son las mayormente afectadas, pero también las más contestatarias de estos procesos, donde la gentrificación evidencia los impactos de las políticas neoliberales sobre estos grupos sociales. Ello debido a un incremento en el consumo de tipos estándares de departamentos como commodities, con una cierta apariencia global (Borsdorf et al., 2007). En este contexto, la ciudad neoliberal se muestra como una ciudad fuertemente conflictuada. Paulsen (2014), para el caso de la comuna de Santiago-centro, centra su atención en los cambios socioespaciales y las organizaciones de resistencia creadas en el barrio Yungay, analizando los negocios inmobiliarios enmarcados en programas de renovación urbana impulsados desde la década de 1990. Destaca como impactos territoriales gatillados por estas políticas el desplazamiento de población y los cambios en la morfología, los cuales dan paso al fenómeno urbano de la patrimonialización.

Otro ejemplo de los impactos de la "patrimonialización" en las ciudades chilenas lo plantea la cuestionada gestión patrimonial desarrollada en el Valparaíso post Declaratoria de Patrimonio de la Humanidad (Caimanque, 2015). A partir de esta experiencia se genera un amplio aprendizaje acerca de cómo los efectos de la declaratoria han estado más vinculados al auge de la economía del patrimonio cultural, que a un desarrollo en términos de protección patrimonial o de participación social (Guerrero, 2013: 7; Guerrero, 2012). En efecto, como plantea 
Andueza (2010), el denominado Plan Valparaíso, nombre con que se nomina a la Comisión Presidencial Asesora para el Desarrollo de Valparaíso de 2002, que junto con la Municipalidad correspondiente generó un dispositivo patrimonial centrado en el emprendimiento y los negocios patrimoniales y no en crear una institucionalidad pública eficiente que regulara que la puesta en valor fuera en beneficio de la ciudad y sus habitantes (García, 2010), no existiendo una política pública clara que se hiciera cargo del desigual proceso de transformación que planteó la "patrimonialización" de la ciudad.

Por su parte, en el contexto más específico del patrimonio industrial, López \& Vidal (2012) han planteado, a partir de un análisis crítico de la situación de Lota post cierre de la minería del carbón, la necesidad de articular el turismo cultural con la revitalización del patrimonio industrial desde una mirada holística y sustentable, planteando la necesidad de perfeccionar estrategias integradas de puesta en valor y de mitigación de los impactos ambientales de modo de impulsar iniciativas sostenibles de reutilización en la fase postindustrial.

\section{El patrimonio como "recurso" para las comunidades}

No obstante lo anterior, para entender las prácticas emergentes de apropiación del patrimonio nos parece central entender cómo se dan los procesos de adopción del "discurso patrimonial" por parte de las comunidades locales, en el marco de un nuevo paradigma de construcción de una "política de la identidad" (Hall, 2003) basada en la cultura como recurso.

Como punto de partida cabe reconocer el nuevo rol que juega la identidad en los procesos de resistencia, conflicto y desarrollo local que plantean las comunidades urbanas (barrios) en relación al patrimonio en el actual contexto globalizador. Con Castells (2003) entendemos que la globalización económica e informacional determina la existencia de un conjunto de cambios subjetivos que ocurren a nivel del individuo y las culturas de las ciudades. Dicho impacto plantea la ampliación de las posibilidades de construir vínculos de arraigo y pertenencia territorial La identidad y el arraigo a un territorio devienen en recursos tanto para el desarrollo de comunidades, instituciones como individuos.

Por otro lado, siguiendo a Hall (2003) es sostenible plantear que identidad cultural -y dentro de ella la identidad de un territorio- no es una cuestión sólo del pasado y del presente, sino sobre todo, del futuro pues se trata de un proceso constante de construcción y reconstrucción, siendo relevante entender el uso y apropiación que hacen las comunidades y grupos culturales de una "narrativa" o una "retórica de la identidad".

Dentro del renacer de las identidades locales el patrimonio adquiere centralidad como herramienta de defensa ante los amenazantes procesos de expansión urbana, inmobiliaria y segregación social que parecieran predominar en el actual modelo de ciudades neoliberales latinoamericanas. Así lo marca la reciente experiencia chilena. La emergencia de una preocupación inédita de la ciudadanía por el patrimonio pareciera provenir antes que del impacto de una política pública pública de puesta en valor, de la reacción de los habitantes de comunidades, barrios, poblaciones, pueblos y villas, que reivindican el uso y apropiación del patrimonio como una potente arma de defensa ante los procesos de metropolitanización que gatillan actores público-privados en los procesos de renovación urbana (Collin, 2014). 
Ejemplos representativos de esta tendencia son los movimientos de defensa barrial que desarrollan en el AMS de Santiago primero a fines de los noventa en Barrio Bellavista (Sagaris, 2014; Ducci, 2004) y posteriormente a mediados de dos mil en los Barrios Yungay y Matta (Paulsen, 2014; GORE-SUBDERE, 2010). En particular se trata de movimientos que transitan de "la protesta a la propuesta" (GORE-SUBDERE, 2010), destacándose en particular el proceso de declaratoria como zona patrimonial de Yungay en 2008 , producto de un estudio y propuesta realizada por los propios vecinos del barrio. Otra experiencia significativa la expresa los más recientes expedientes patrimoniales presentados por ciudadanos organizados de los Barrios Matta Sur (Agrupación Matta Sur, 2012) y por la población La Legua (Consejo de Pobladores de La Legua, 2013) en el AMS. Guerrero (2014) ha puesto de relieve el surgimiento y rol de los movimientos patrimonialistas en Valparaíso, destacando que el planteamiento del patrimonio como derecho social ha sido el eje discursivo de las organizaciones sociales. Guerrero (2014) ha puesto de relieve el surgimiento y rol de los movimientos patrimonialistas en Valparaíso, destacando que el planteamiento del patrimonio como derecho social ha sido el eje discursivo de las organizaciones sociales.

Por otro lado, desde una perspectiva más estructural, Inzulza y Galleguillos (2014) realizan un análisis de los fenómenos de gentrificación en los barrios El Llano Subercaseaux -barrio pericentral histórico localizado en la comuna de San Joaquín-, y Parque Violeta Cousiño, barrio periférico emergente de la comuna de Peñalolén, poniendo de relieve la relación entre las estructuras barriales resultantes y las implicancias de los fenómenos de diferenciación socio-espacial para la sustentabilidad urbana. En ese marco, los autores promueven el desarrollo de un enfoque del urbanismo ciudadano caracterizado por políticas urbanas centrada en la valoración de la realidad plural y diversa de los barrios y comunidades, con el desafío permanente de adaptar y flexibilizar las propuestas de intervención territorial, en un marco de regeneración urbana barrial integral. Por su parte, en el caso de Valparaíso, la puesta en valor como Patrimonio de la Humanidad activa la movilización de los ciudadanos para hacer patente la defensa del patrimonio barrial ante la turistificación y gentrificación post declaratoria y ante el impacto de proyectos de infraestructura que amenazan con expropiar y privatizar el borde costero (Andueza, 2010).

Para Yúdice (2002), en el contexto complejo de las relaciones de poder emerge el "recurso de la cultura". Se trata de la apropiación que hacen los actores territoriales de los recursos que les provee su propia identidad, en este caso sus atributos patrimoniales tanto materiales como inmateriales para poder negociar un mejor posicionamiento a nivel de la región y la ciudad. Yúdice parte de la base de que los actores culturales acuden hoy a la lógica de la performatividad para desenvolverse en el escenario global, potenciando sus prácticas como recurso, lo que crea un "efecto de posicionamiento" antes los diferentes actores que componen el campo cultural. Aún identidades que plantean resistencia cultural, como inicialmente plantean los movimientos barriales que reivindican el patrimonio, se ven obligadas a adecuarse a la lógica de la performatividad, ocupando en este caso su historia y sus activos culturales en pos de la gestión de su propio desarrollo local.

En ese sentido el relato patrimonial apelará a la búsqueda de una historia colectiva compartida por quienes se adscriben a un determinado espacio, historia que además otorga sentido y continuidad en el tiempo al territorio. La narrativa patrimonial estará inserta en un relato más amplio de la identidad territorial que incorpora un conjunto de características particulares dadas por sus atributos identitarios básicos como su historia, sus ritos, fiestas y expresiones culturales prototípicas. 
Finalmente, la puesta en valor de un objeto como patrimonio no es solamente competencia de expertos o científicos sino de las personas que lo conocen, lo miran, lo habitan o lo usan quienes también son actores en este proceso. De hecho, Deacon \& Smeets (2013: 133) constatan que las Convenciones para el Patrimonio Mundial y el Patrimonio Inmaterial de la UNESCO son muestra inequívoca de una tendencia a valorar más el papel que desempeñan actualmente las comunidades en la identificación, gestión y preservación de su patrimonio. En ese marco emergen nuevos actores ciudadanos, que a partir de un conflicto urbano, socio-ambiental o como defensa ante una catástrofe se organizan en torno al significante patrimonial, activando como un recurso comunitario vivo su patrimonio e identidad, aportando nuevos enfoques y práctcas que descongelan la noción oficial de patrimonio articulada en torno a la monumentalidad y el predominio de lo material.

Siguiendo a Carrión (2010) en el actual escenario de globalización surge el sujeto patrimonial, el que hace referencia a una relación social que contiene tres aspectos principales: el momento (cuándo), lo que se hereda (qué) y los actores específicos que transfieren y reciben (quién). La definición de sujeto patrimonial implica que lo patrimonial existe en la medida en que uno o varios sujetos lo reconocen, apropian y protegen. En ese marco las comunidades dan una lucha por la democratización del patrimonio desarrollando una apropiación del mismo.

\section{Sujetos patrimoniales y Plataformas urbanas en el Concepción Metropolitano: metodología y análisis de casos}

El estudio abordó bajo la metodología de estudio de casos la experiencia de 3 colectivos urbanos que desarrollan prácticas de rescate del patrimonio en el Gran Concepción, a saber, Proyecta Memoria de Concepción, el Consejo Comunal para el Patrimonio de Tomé, y la Organización Talcahuano Patrimonial. Para esto se desarrollaron entrevistas a 7 dirigentes, al menos dos por cada colectivo ${ }^{6}$, realizándose visitas a terreno, observación participante en sus intervenciones urbanas y analizando sus plataformas digitales (páginas web, Facebook, Twitter, blogs entre otras).

El análisis de cada caso consideró una reconstrucción de la historia, objetivos y acciones desarrolladas por cada colectivo en defensa del patrimonio, en segundo lugar, sus estrategias y metodologías de activación patrimonial; en tercer lugar, su enfoques y visiones sobre el patrimonio, analizando y finalmente, en cuarto lugar, un abordaje inicial de cómo, como agrupaciones articulan o no el patrimonio con el proyecto de desarrollo local en sus diversas escalas de acción (escala comunal, regional, nacional).

El análisis comparativo nos permite plantear que la organización Consejo Comunal para el Patrimonio es la más antigua de los tres colectivos estudiados iniciando su acción en 2009, casi un año antes del terremoto. La agrupación comienza a articularse a partir de un conflicto urbano que moviliza y articula a los "tomecinos" en la defensa del principal espacio público de Tomé, la Plaza de Armas, que pretendía ser remodelada por el Municipio instalando baños públicos en su sector central generando un importante daño al carácter de espacio público al interrumpir un espacio de flujo y encuentro. De este primer hito de articulación que da origen a la agrupación, los actores rescatan que se haya logrado defender más allá de su antigüedad y valor histórico el valor de uso

Se entrevistó a Álvaro Pinochet, y Reiner Cabrera, por parte del Consejo Comunal de Tomé; a Hilda Basoalto y Patricio Mora, arquitectos por parte de Proyecta Memoria, y Rodrigo Núñez, Luis Eugenio Salinas y Geraldinne Bascur, arquitectos por parte de Talcahuano Patrimonial. 
de un espacio patrimonial como la plaza de armas, un espacio público de encuentro que cumple un rol central en activar la vida urbana en una comuna pequeña que tiene poco espacios públicos de calidad que permitan su auto reconocimiento e identificación como comunidad.

La organización asume posteriormente a la defensa de la demolición de un edificio patrimonial (Casa Hinrichsen) acción en la que sufren una dura derrota al no evitar que fuera demolido. Este hito marca el establecimiento de un cambio de estrategia de la organización que va desde el conflicto a la propuesta de una política de gestión patrimonial a nivel comunal. La acción central que moviliza a la organización los últimos año es es su lucha por la defensa de la Fábrica de Paños Bellavista Tomé. En esta iniciativa la organización participa apoyando primero la presentación de un expediente de declaratoria patrimonial al Consejo de Monumentos Nacionales por parte del Municipio de Tomé en 2014, y posteriormente movilizándose por su aprobación, siendo el eje motor de una movilización ciudadana que logra detener el proyecto de cambio de uso de suelo presentado por los propietarios al municipio que amenazaba con la demolición del recinto, siendo aprobada la declaratoria como Monumento Histórico nacional de toda la fábrica el 13 de Abril de 2016. En el marco de esta "victoria patrimonial" es que la agrupación instala actualmente la demanda de generar una gestión patrimonial participativa de la fábrica que liderada por la comunidad organizada permita dar sustentabilidad a sus usos futuros lo que configura una oportunidad inédita en Chile para gestionar el patrimonio industrial desde un modelo de desarrollo distinto al público-privado.

Talcahuano Patrimonial es la organización más nueva de las tres, se constituye formalmente como agrupación con personalidad jurídica recién en Mayo de 2012, si bien se activa en términos informales en 2011, a partir de la fuerte reacción ciudadana ante el abandono que sufre el patrimonio de Talcahuano por parte de la política nacional de reconstrucción. Se trata de una resistencia que se cataliza a través de las redes sociales y que congrega en la defensa del "patrimonio chorero" a un conjunto de profesionales, arquitectos, historiadores y estudiantes de arquitectura. Como plantean sus informes para la agrupación, el proceso de reconstrucción post terremoto -liderado por el MINVU- y el Municipio no visibilizan el patrimonio de Talcahuano, demuele edificios históricos y desarrolla políticas de renovación urbana que no incluyen sus lugares y sitios históricos. En ese marco se puede plantear que la organización se encuentra aún en una primera fase defensiva y de resistencia, una "entidad conservacionista o de resistencia" según definición de Hernández (2008: 48-49), que los lleva a desarrollar sus primeras acciones de protesta en espacios públicos y en reuniones de sensibilización con autoridades.

Como plantea uno de sus miembros, se formalizan como organización a partir de la necesidad de hacerse cargo de la gestión de un tema del cual ni el municipio ni el gobierno nacional a partir de una política de reconstrucción se estaban haciendo cargo. En ese marco establecen como línea base la recuperación de un sentido de identidad en la comunidad "chorera". Es en el marco de la sensibilización de la comunidad con un fuerte componente histórico y de recuperación tanto del patrimonio tangible como intangible la que caracterizará su activación patrimonial cuyos principales hitos están dados por dos tipos de acciones. Por un lado, su lucha centrada en la defensa patrimonial del abandono simbolizado en la defensa de dos hitos: el Molino Brañas Mathieu y el

Trabajo que reflexiona sobre las semejanzas y diferencias de las organizaciones inscritas en el movimiento social patrimonialista español. Concluye que las organizaciones coinciden en su inquietud por el patrimonio, pero unas hablan del pasado como resistencia y otras como proyecto, distinguiendo que ello se traduce en diversidad de discursos y acciones. 
barco RAM Poderoso. Por otro lado, su énfasis histórico en la educación patrimonial expresado en la elaboración de cuatro rutas patrimoniales, dos señaléticas patrimoniales en el borde costero y la premiación y reconocimiento de vecinos destacados al "patrimonio chorero".

Finalmente, la organización Proyecta Memoria de Concepción representa una variante distinta de organización ciudadana liderada en su mayoría por arquitectos jóvenes que se articulan a partir del contexto que marca el Terremoto y Tsunamis del 27 de Febrero. Es así como el impacto de la catástrofe activa el interés de un colectivo de estudiantes y profesionales jóvenes de universidades de Concepción, que se asocian bajo el nombre de Bío Bío Proyecta. A partir del trabajo voluntario de los estudiantes de arquitectura de Concepción se comienza a constituir un colectivo, Proyecta Memoria, que se auto-convoca para proyectar como foco de su trabajo la defensa y revaloración del patrimonio urbano tangible e intangible a nivel local, regional y global desde una perspectiva distinta que innova y coloca el foco en la relación memoria/patrimonio material. En ese marco, Proyecta Memoria adquiere gran visibilidad nacional como colectivo de urbanismo emergente al crear en Mayo de 2010 la Guía de recuperación y reutilización de escombros simbólicos en el espacio público, presentando esta experiencia en la XII Bienal de Arquitectura de Venecia en 2010. Otras iniciativas que desarrolla son exposiciones de valorización del escombro simbólico en Talcahuano y Lota durante 2011, la participación en el debate para rescatar y reutilizar las ruinas del Edificio Alto Río de Concepción como un futuro centro de investigación y gestión para desastres naturales, y un conjunto de acciones entre las que destacan intervenciones urbanas como el "Hipocentro de Memoria", año 2014, y su trabajo de movilización expresado en la campaña \#Sí a los adoquines de Concepción el 2013.

\section{Estrategias y metodologías de activación patrimonial}

Se puede plantear que las agrupaciones y colectivos en tanto se constituyen como sujetos patrimoniales, que se hacen cargo de gestionar su patrimonio, desarrollan diferentes tácticas y estrategias de resistencia patrimonial a través de las cuales activan y dan contenido y movimiento a una noción de patrimonio previamente congelada en el conservacionismo o inexistente. En el nivel táctico podemos situar todas las acciones de resistencia a conflictos específicos que afectan su patrimonio. Como parte del estudio se detectó el desarrollo por todas las agrupaciones de al menos cuatro niveles de acción:

- Acciones ante los entes de gobierno comunal

- Acciones ante la política pública nacional identificada en el CMN

- Acciones de movilización ciudadana

- Acciones de urbanismo táctico

Destacan en el caso del Consejo Comunal para el Patrimonio de Tomé, que sus tácticas de activación se focalizan en influir en el municipio primero a partir de movilizaciones contra la privatización del espacio público de la plaza, solicitando como la ley municipal lo plantea una audiencia pública para ver el caso logrando detener el plan municipal; para luego generar un trabajo de co-diseño con el municipio, de un nuevo proyecto, lo que fructifica en una posterior alianza para que el Municipio presente la propuesta de declaratoria de Monumento Nacional de la Fábrica Oveja Bellavista ante el Consejo de Monumentos Nacionales. La declaratoria de la fábrica es aprobada en Abril de 2016, luego de una movilización ciudadana de tres meses, que incluyó la recolección de más de 5000 firmas y el fuerte uso de redes sociales siendo fundamental para esta el impulso 
de la ciudadanía tomecina organizada en la Mesa Ciudadana para el Patrimonio, que liderada por el Consejo Comunal logró integrar a más de 20 organizaciones vecinales y comunitarias de Tomé.

En términos de su estrategia de movilización de la ciudadanía, además de participar en el movimiento de apoyo a la Declaratoria de Bellavista Tomé, coloca énfasis en una metodología que combina la visibilización del patrimonio comunal a través de rutas patrimoniales comunales con la discusión social de una propuesta de gestión patrimonial de más largo aliento con la comunidad. En el caso de las rutas o recorridos patrimoniales se trata de un ejercicio por visibilizar el patrimonio de toda la comuna de Tomé, realizándose cuatro rutas patrimoniales entre 2011 y 2014. (Figuras $\mathrm{N}^{\circ} 1$ y $\mathrm{N}^{\circ} 2$ )

Figura $\mathrm{N}^{\circ} 1$

Visita a instalaciones abandonadas, Ex Fábrica Italo Americana de Paños (FIAP),

Día del patrimonio 2014

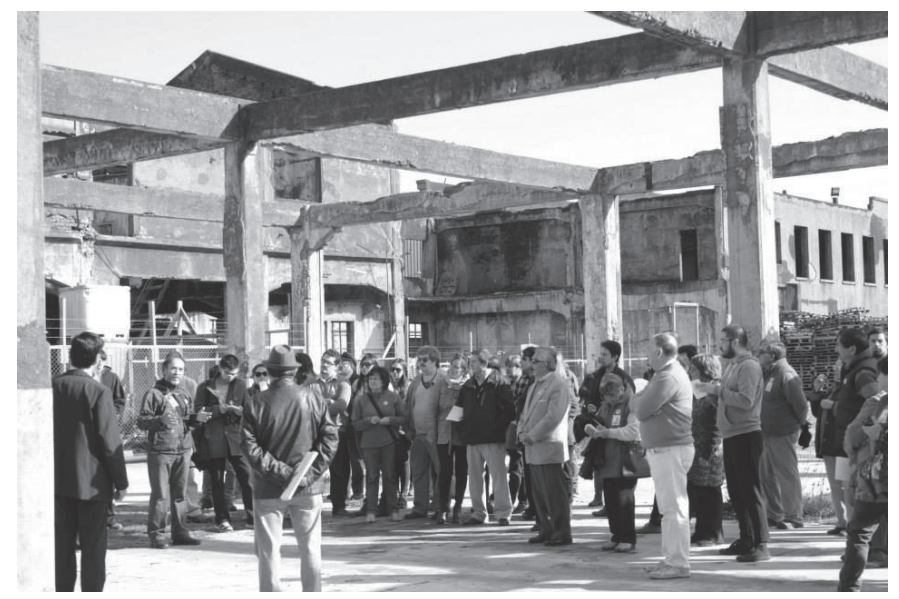

Fuente: Consejo Comunal para el Patrimonio de Tomé

Por su parte, las jornadas de reflexión patrimonial y de discusión sobre la declaratoria de la fábrica tienen como objetivo generar una masa crítica que sea capaz de apropiarse de su patrimonio, organizando a la fecha cuatro encuentros en donde se discute la propuesta de Declaratoria de Monumento Nacional de la Fábrica Bellavista Oveja Tomé presentada por el municipio en marzo de 2014. El objeto de estas actividades es poder entregar a la autoridad municipal, (que es la que presentó la solicitud de Declaratoria), a la comunidad y al CMN un consolidado de qué es lo que espera la comunidad tomecina y en particular la del barrio Bellavista con la declaratoria de Monumento Nacional de la fábrica Bellavista, qué se debería proteger, cuál es la importancia de su declaratoria y qué representa la Fábrica para la comunidad.

Es sustantivo destacar como en las conclusiones de este trabajo de discusión sobre la Declaratoria se concluye que el reconocimiento a la industria Bellavista Oveja Tomé está directamente imbricado con la puesta en valor del barrio Bellavista de Tomé asociado a un pasado industrial textil: 
Figura $\mathrm{N}^{\circ} 2$

Recorrido interior ex Fábrica Bellavista, Día del patrimonio 2015

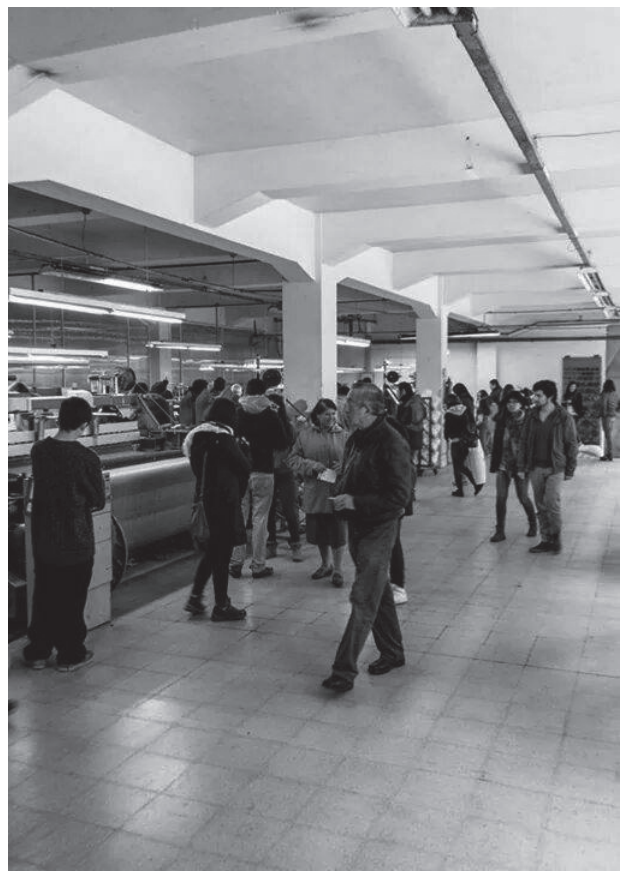

Fuente: H. Basoalto

"Todos estos antecedentes permiten entender que no es solamente el inmueble como objeto arquitectónico lo que determinamos como patrimonial, sino que es la industria fundada en conjunto con su pueblo lo que se convierte en la característica esencial de esta comunidad, esto principalmente por el espíritu industrial y empresarial que distingue a sus habitantes". (Conclusiones Jornadas de Trabajo Discusión Declaratoria, octubre 2014)

En términos estratégicos el Consejo Comunal para el Patrimonio asume una acción heterogénea basada en una gestión organizacional que trabaja en red a una escala comunal articulando vínculos con las organizaciones territoriales y funcionales de la comuna y estableciendo un fuerte lazo con el Consejo de Monumentos Nacionales, alianza que potencia el objetivo de informar a la comunidad sobre la ley de monumentos nacionales y sus principales instrumentos de protección patrimonial (Declaratoria Zona Típica, Monumento Histórico).

En Talcahuano Patrimonial el trabajo de activación patrimonial se centra en la sensibilización de las instituciones nacionales y comunales como el CMN y el Municipio de Talcahuano, el que no obstante la energía desplegada no logra conseguir, en la voz de los actores, todos los frutos esperados. La citada declaratoria del edificio del "Molino Brañas Mathieu" parece ser una demanda que articula y visibiliza la actual lucha de Talcahuano Patrimonial. Si bien se logró detener un decreto de demolición y el CMN levantó un informe en donde declara que el recinto está en buen estado, actualmente subsiste el peligro de que el recinto sea vendido por el propietario que es un particular para instalar un terminal de buses no habiéndose aún entregado respuesta a la solicitud de declaratoria entregada por la comunidad el 2012 (Figura $N^{\circ} 3$ ). 
Figura $\mathrm{N}^{\circ} 3$

Ex Molino Brañas Mathieu en el contexto del puerto de Talcahuano

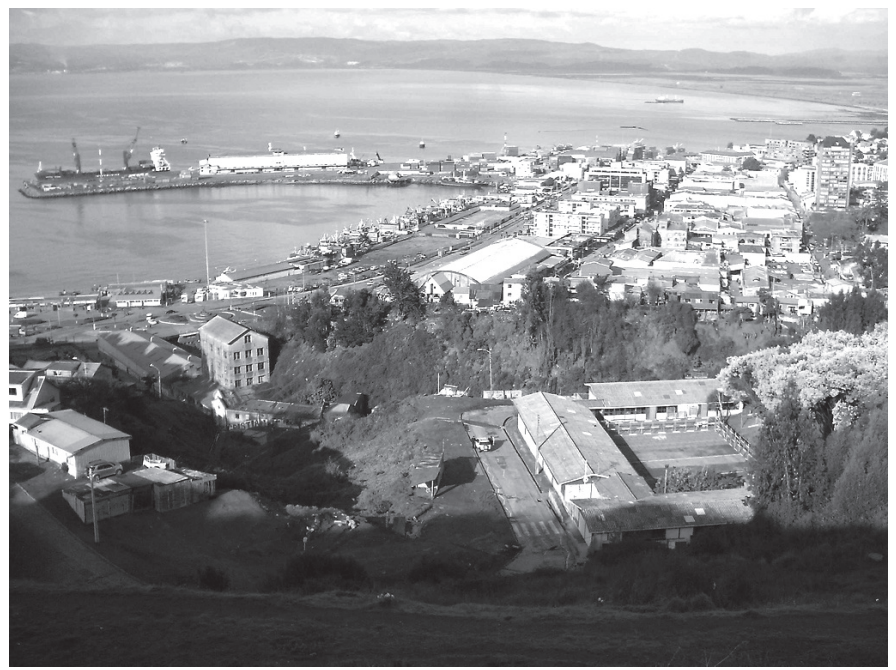

Fuente: G. Bascur

En el caso de Talcahuano Patrimonial sus tácticas de activación patrimonial innovan en el plano de la educación patrimonial al desarrollar con financiamiento del FNDR durante 2014 cuatro rutas patrimoniales y dos señaléticas en el borde costero -frente al Coliseo La Tortuga y en el sector de La Poza- informando a la comunidad los hitos patrimoniales existentes en ese lugar con datos levantados a partir de la propia investigación de la organización. Las rutas patrimoniales son Ruta Borde Costero Blanco Encalada (Figura No 4), Ruta cementerio No 1 de Talcahuano de Disidentes, la "Ruta Talcahuano Secreto" y una Ruta Patrimonial Marítima por diferentes Caletas vía Tumbes: "...las acciones en ese sentido son los recorridos que hacemos, o sea como quien dice la presencia en la ciudad para la gente común son nuestros recorridos, porque a veces llevamos a alguien con un tambor y la gente dice y estos locos que están haciendo?" (Luis Eugenio Salinas, Director Talcahuano Patrimonial).

La impronta del trabajo patrimonial de la agrupación está en el desarrollo de un importante trabajo de investigación sobre la historia e identidad local ${ }^{8}$, que plantea un enfoque innovador en cuanto a la valoración del patrimonio humano entregando distinción a personajes ilustres de la comuna que han desarrollado una labor relevante por el patrimonio.

En el caso de Proyecta Memoria la apropiación táctica tiene que ver con otro tipo de acciones como aprovechar la coyuntura de la re-construcción post terremoto para establecer un nuevo lenguaje y metodología de acercamiento a la defensa del patrimonio, fuertemente enlazada con acciones de urbanismo táctico (Lydon, 2012; Steffens et al., 2013) o ciudadano, teniendo un punto

La Agrupación rescata a través de un trabajo historiográfico autodidacta, y que es difundido en dípticos patrimoniales, personajes históricos que forman parte de la historia de Talcahuano como Thomas Andrews Sharpe, marino inglés que participa de la guerra de la Independencia; David Fuentes, pionero de la aviación chilena, y Friederich Kucck, maquinista alemán del crucero Dresden que queda varado en Isla Quiriquina durante la Primera Guerra Mundial (Fuente: archivo Talcahuano Patrimonial). 
RUTA PATRIMONIAL CENTRAL DEL PUERTO DE TALCAHUANO

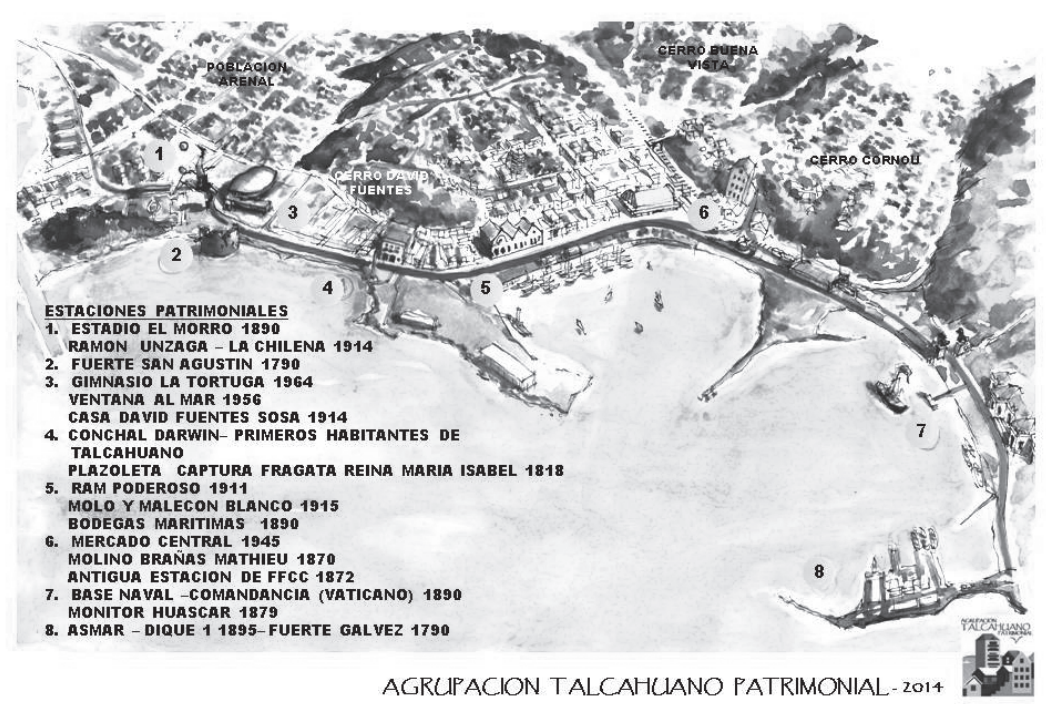

Fuente: Agrupación Talcahuano Patrimonial.

de vista crítico respecto a la sola conservación del patrimonio, que ven reflejada en los actuales procesos de "patrimonialización":

"...nuestro propósito final es un bien en nuestra sociedad, y por eso te digo, lo principal es que nosotros somos ciudadanos, como arquitectos, como profesionales tenemos una responsabilidad y nos mueve el fin de responsabilidad, de intentar mejorar un sistema que está mal, es como lo que... yo sí me puedo sentir que somos un grupo cuestionador de las políticas que están ahora ¿ya?, eso sí. No sé si somos emergentes o en que estamos... bueno puede ser emergentes porque estamos, lo que hicimos nosotros fue algo innovador en ese sentido, instalamos una política que nunca nadie la tomó y que ahora la están tomando" (Hilda Basoalto, Directora Proyecta Memoria).

Como ejemplos demostrativos del urbanismo táctico desplegado por la organización se puede analizar tres actividades, por un lado el "Hipocentro de Memoria" (Figuras No 5 y 6 ) y las "Alarmas de Memoria" y por otro su trabajo de activación ciudadana expresado en la movilización \#Sí a los adoquines de Concepción:

"pero también estamos desarrollando otro tipo de intervenciones que se llaman los Hipocentros de Memoria que son como llamados de atención en inmuebles que son vulnerables a la destrucción por catástrofes naturales o por el mismo olvido de las personas que es como más intervención land art, a través de texturas en el piso, que representan como un hipocentro de atención. Y la otra, que también es utilizando el espacio público, pero es sonoro, que son Alarmas de Memoria, que son para las conmemoraciones de los 
terremotos o catástrofes en general, que, a la hora exacta en donde ocurrió la catástrofe y el día, hacemos a través de campanas y alarmas llamados de atención..." (Patricio Mora, Presidente Fundación Proyecta Memoria).

\section{Figura $\mathrm{N}^{\circ} 5$}

Hipocentro llevado a cabo en histórico Muro de Calle Tucapel (Monumento Nacional), en Concepción

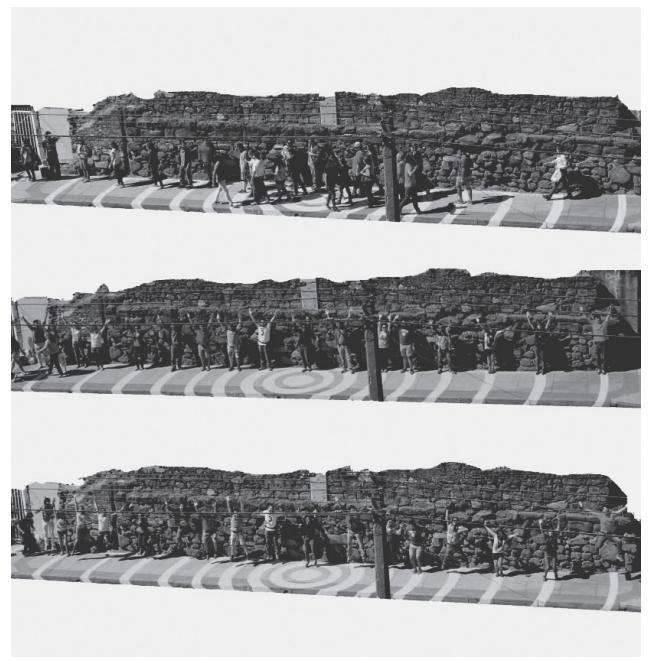

Fuente: D. Labra.

Figura $\mathrm{N}^{\circ} 6$

Jóvenes estudiantes ejecutando el Hipocentro Muro Calle Tucapel en Concepción, 2014.

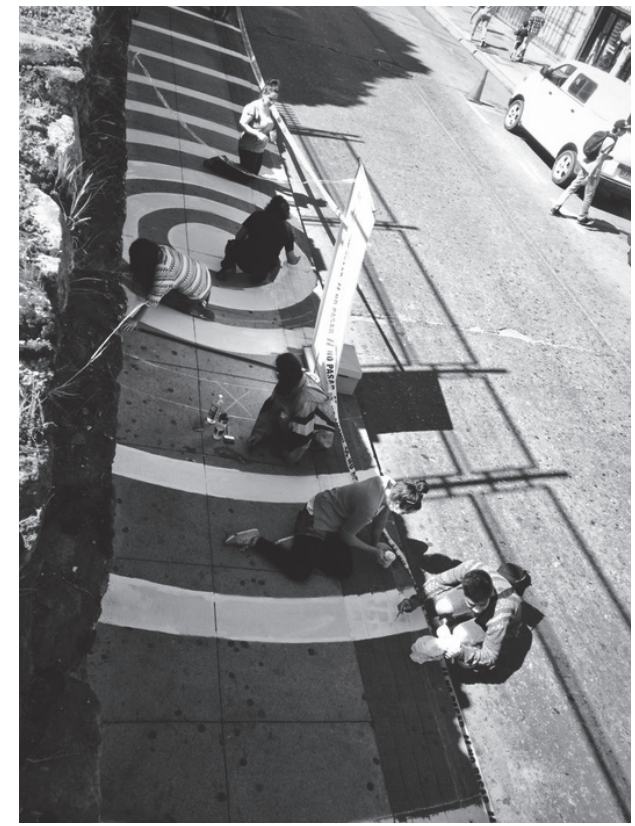

Fuente: P. Mora. 
En el caso de \#Sí a los adoquines de Concepción la agrupación lidera una acción ciudadana por la recuperación del patrimonio de los barrios céntricos que se ve amenazado por el desarrollo del plan de pavimentación del centro por parte del Municipio de Concepción, planteando una acción que combina una fuerte campaña por redes sociales de Facebook y Twitter con la participación del equipo de arquitectos como asesores de la comunidad en talleres en que se explica el valor del adoquín.

Figura $\mathrm{N}^{\circ} 7$

Campaña \#Sí a los adoquines de Concepción

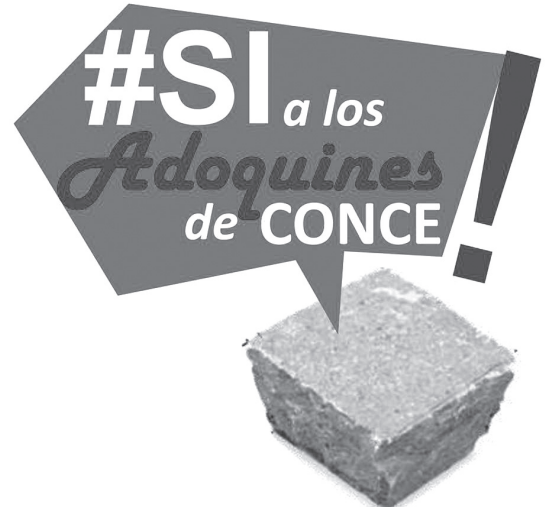

Fuente: Proyecta Memoria.

Figura $\mathrm{N}^{\circ} 8$

Campaña \#Sí a los adoquines de Concepción, situación calle Pelantaro esquina Las Heras, noviembre de 2014

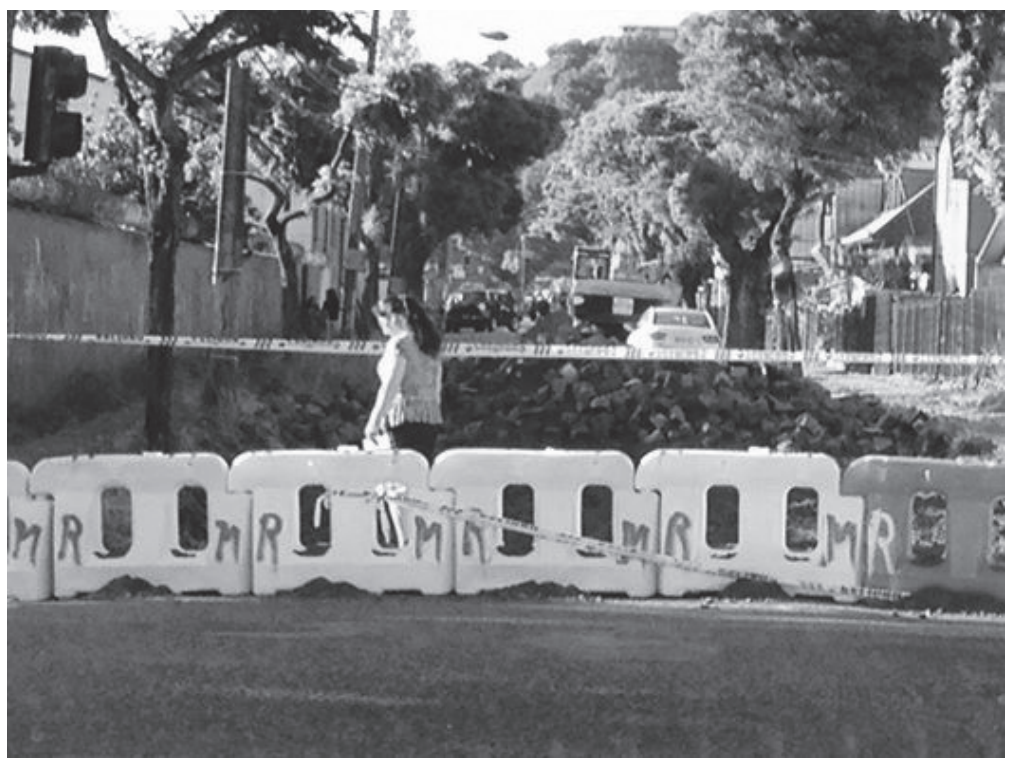

Fuente: Proyecta Memoria. 
En el nivel estratégico de la acción de Proyecta Memoria distinguimos la existencia de propuestas de mediano y largo plazo que van más allá de la coyuntura que plantean una visión crítica al paradigma hegemónico conservacionista. Como plantea Mora, la visión estratégica hace extensiva su visión a todo tipo de catástrofes tanto naturales como artificiales que ponen en riesgo la conservación del patrimonio arquitectónico. Se trata de un trabajo a nivel tanto de la escala local-regional como nacional e incluso internacional o global. En ese sentido prima el establecimiento de una misión que asume una escala que articula lo nacional con lo local, ya que se trata de preservar y proteger el patrimonio arquitectónico destruido por catástrofes naturales y artificiales (en Chile), a través de técnicas, principios y políticas de reutilización y reciclaje de escombros simbólicos en el espacio público y/o abierto. El colectivo establece tres líneas de trabajo: una es la reutilización de los escombros que provienen de inmuebles patrimoniales -que no necesariamente tienen que ser catalogados oficialmente como patrimonio (ser monumento nacional y/o parte de una zona típica) con los que la comunidad establece un sentimiento y sentido de arraigo, desarrollando tácticas urbanas de activación patrimonial. Las otras dos líneas de intervención tienen relación con la memoria de los espacios patrimoniales y la sensibilización para su protección dado el entorno particular de vulnerabilidad que tiene el patrimonio en relación a catástrofes naturales tanto en la VIII Región como en Chile.

Es con el objetivo de diferenciar y dar continuidad y financiamiento a sus estrategias de trabajo que el colectivo decide establecer un funcionamiento que da origen a dos personalidades jurídicas que permiten la consecución de recursos que permitan desarrollan acciones que vayan más allá del nivel táctico reactivo. Una relacionada directamente con la Memoria (Proyecta Memoria) y otra con la relación Memoria y Catástrofe (Fundación Alto Río). En efecto, en ese marco se crea la Fundación Alto Río9 , la que nace a partir de su trabajo con los ciudadanos afectados por el terremoto que vivían en los edificios colapsados. Con la creación de una Fundación se plantea como misión apoyar la consolidación de una cultura de gestión del riesgo de desastres en Chile.

\section{Nociones y visiones sobre el Patrimonio}

Habiendo analizado su trayectoria de acción se hace necesario determinar cuales son las visiones de patrimonio que plantean los colectivos patrimoniales de la AMC. En relación con su acercamiento al patrimonio encontramos una clara diferencia entre las Agrupaciones Consejo Comunal Tome y Talcahuano Patrimonial que constituyen organizaciones que reivindican una defensa territorial del patrimonio del Concepción Metropolitano centrada en una escala comunitaria. Esta articulación del patrimonio con la defensa de la identidad local esta presente en sus nociones de patrimonio. Por un lado Tomé articula como eje central la valoración comunitaria del patrimonio, vinculando este con su identidad territorial específica de "tomecinos": "La valoración que hace la comunidad a algo tangible o intangible, algo que en la comunidad se ha manifestado durante un tiempo y que tiene un valor especial y que le da una identidad especial a un territorio determinado." (Álvaro Pinochet, Presidente Consejo Comunal de Tomé)

A partir del Proyecto Fundación Alto Río se plantea como estrategia de mediano y largo plazo el educar y preparar a la población ante futuros desastres de origen natural, entregándoles información, capacitación y conocimientos para estar mejor preparados personal y colectiva mente, mejorando su capacidad de organización y respuesta frente a crisis de gran escala. 
En el caso de Talcahuano su noción de patrimonio tiene un énfasis más histórico de defensa de un modo de vida y una "cultura chorera" que se siente amenazada por los procesos de desarrollo urbano: "es lo que se requiere resguardar, preservar y que se vincula con la historia de la ciudad (...) con sus tradiciones, con un sistema de vida, en este caso la actividad pesquera, la actividad industrial hay todo un tema de vida que Talcahuano tiene y a partir de ahí nosotros nos vamos hacia allá" (Rodrigo Nuñez, Director Talcahuano Patrimonial )

Por su aporte la agrupación, Proyecta Memoria presenta una propuesta innovadora en relación a la noción oficial de patrimonio orientada a modificar la forma en que en Chile se salvaguarda el patrimonio arquitectónico propuesta muy marcada por la experiencia de destrucción del terremoto del 27 de febrero de 2010, "nosotros trabajamos el rescate del escombro como ente simbólico, el escombro no sólo representa el edificio sino lo que la comunidad hacía en ese edificio y por eso son recuerdos y por eso esos recuerdos no pueden ser olvidados [...] son mi memoria" (Hilda Basoalto, Presidenta Proyecta Memoria).

Para la organización el terremoto genera la necesidad de "resetear" la forma tradicional de acercarse al patrimonio, expresada en el modelo de ppatrimonialización", que representan las solicitudes de declaratoria patrimonial al Consejo de Monumentos Nacionales (CMN), y abrir un nuevo camino para que las comunidades se apropien de su memoria patrimonial a través de una metodología de recuperación y reciclaje de los restos de edificios patrimoniales, los "escombros" que si bien constituyen patrimonio material, construyen y constituyen parte del espacio público, rescatando su significado para las personas.

\section{Articulación del Patrimonio como herramienta de Desarrollo local}

Finalmente, un elemento que nos parece pertinente abordar es la capacidad que tienen los sujetos patrimoniales de dar sustentabilidad a sus prácticas de defensa patrimonial e identitaria a través del establecimiento y disputa de una propuesta de desarrollo más amplia que la coyuntural o meramente restringida a la comunidad de un barrio. En ese marco se podría decir que las tres agrupaciones se encuentran a medio camino de elaborar una propuesta de desarrollo patrimonial a escala territorial comunal o regional.

En el caso de Proyecta Memoria a través de su praxis -teoría y acción sobre el patrimonio- se constata la desconexión entre política nacional y ordenamiento territorial en donde las comunidades patrimoniales quedan sin instrumentos prácticos para cautelar que la protección del patrimonio queda inscrita en forma perentoria en los instrumentos de planificación comunal y regional. Un ejemplo patente que consignan es el fracaso relativo que sufrió la organización al activar la defensa de los adoquines del centro de Concepción participando de un proceso de participación de dos semanas en que la comunidad votó a instancias del municipio por el retiro o no de los adoquines de calle Rozas, ganando la opción de retirar los adoquines de piedra para facilitar la pavimentación con cemento de las calles:

“...hubo un error de la municipalidad porque lo hizo vinculante pero no dio tiempo para la educación, ya que hay mucha gente que es adulto mayor que lo único que quiere es cruzar la calle, que no le interesaba el tema del patrimonio sino que sobrevivir, y la idea era haber llevado a estos mismos ancianos, por ejemplo, llevarlos a Santiago para plantearles que en realidad el problema no es el adoquín sino que es la falta de mantención y que esto sirve 
mucho para un tema sustentable, para el tema del ruido, para el tema del agua... y la identidad que tenía los adoquines de Rozas es como muy parte de ahí." (Patricio Mora, Director Proyecta Memoria)

Por su parte para Consejo Comunal de Tomé el rol que asume la organización es ser un articulador de los intereses de la comunidad tomecina en relación al patrimonio, yendo más allá del trabajo particular a escala barrial a un trabajo que considera la influencia a nivel del gobierno local, en ese sentidos establecen su proyecciones: " dejar legado para gente joven se empiece a interesar más por el tema y seguir incidiendo en las autoridades locales para ir mejorando la normativa y regulación del urbanismo en la comuna y tercero aprovechar la normativa vigente para declarar zonas típicas o en el plano regulador conservación histórica"(Álvaro Pinochet, Director Consejo Comunal Tomé).

En ese marco las conclusiones de las jornadas de discusión de la declaratoria plantean una agenda de temas a abordar en forma urgente para poder gestionar la puesta en valor de la fábrica y del Barrio Bellavista. Sintéticamente se plantea el urgente mejoramiento del Plan Regulador Comunal que no incluye un enfoque de patrimonio siendo fuertemente permisivo para la generación de nuevas edificaciones. En ese marco se propone el desarrollo de planes seccionales adecuados que den directrices de cómo se debe construir respetando la protección de sectores de interés patrimonial, y finalmente se demanda con urgencia la creación de una Unidad de Patrimonio Municipal que haga cargo de la gestión patrimonial de todos los temas a escala de la comuna de Tomé.

En el caso de Talcahuano Patrimonial, la articulación con una escala más amplia de gestión patrimonial es un proceso en construcción, ya que la organización aún se encuentra en una primera fase centrada en la difusión y defensa del patrimonio siendo el desafío ser referentes en relación a la gestión patrimonial a nivel de toda la comuna: "nuestra ambición es ser reconocidos, por tener un rol dentro de la ciudad, haber logrado cosas, que el Molino sea declarado Monumento Nacional (...) y que la gente despierte, despertar a la gente" (Rodrigo Núñez, Director Talcahuano Patrimonial)

No obstante, la organización es consciente que debe ampliar su influencia y alianza con el ente municipal, que aún no se encuentra suficientemente sensibilizado para lo cual se encuentra desarrollando un trabajo incipiente de vinculación la Corporación Municipal de Cultura.

Finalmente, cabe señalar que en relación a la política pública de patrimonio se establecen diferencias entre una lógica que apela a la protección y conservación con base en la Ley de Monumentos Nacionales, planteando sendas declaratorias (Fábrica Bellavista en el caso de Tomé, El Molino en el de Talcahuano) a diferencia de Proyecta Memoria que tiene una mirada más crítica respecto los instrumentos y la mirada misma de la conservación patrimonial, planteando una gestión comprometida con la participación de la comunidad en los procesos de puesta en valor patrimonial:

"Sí. Nada de nuestro trabajo tiene validez si no ha sido visado por la comunidad a la cual va a influir directamente ese proyecto, y por eso nosotros no nos estamos enfocando solamente a proyectos del Consejo de Monumentos que están acogidos a la Ley de Monumentos Nacionales, porque ya, ellos están protegidos pero ¿realmente son muestra de lo que resignifica la gente de su memoria? Eso es una pregunta, porque a veces mucha gente no 
sabe... mira esto está acogido a la ley pero la gente ni siquiera tiene idea y hay otras cosas que son mucho más importantes..." (Hilda Basoalto, Presidenta Proyecta Memoria).

\section{Conclusiones: del concepto tradicional de Patrimonio a la activación patrimonial como práctica de urbanismo ciudadano}

En síntesis, como demuestran los casos analizados, la pregunta por el patrimonio en el Concepción Metropolitano tiene cada vez más relación con el proyecto de futuro que los y las ciudadanas quieren construir (Figura $N^{\circ} 9$ ), un futuro diferente al presente que plantea la ausencia de proyectos de desarrollo local de comunas como Tomé, Concepción y Talcahuano. En estas comunidades el patrimonio emerge como una herramienta y recurso básico para la construcción de un modelo de desarrollo alternativo al de la ciudad neoliberal, que articula las identidades locales con una visión del desarrollo urbano centrado en la calidad de vida de las persona. En ese marco colectivos tan diversos como el Consejo Comunal para el Patrimonio de Tomé, Talcahuano Patrimonial, ó Proyecta Memoria, conforman plataformas que encuentran en el activismo urbano y en un "urbanismo ciudadano" una forma de cambiar políticas de mercado basadas fundamentalmente en el predominio del valor del suelo.

Figura $\mathrm{N}^{\circ} 9$

Distribución espacial de iniciativas y proyectos promovidos por los tres colectivos urbanos

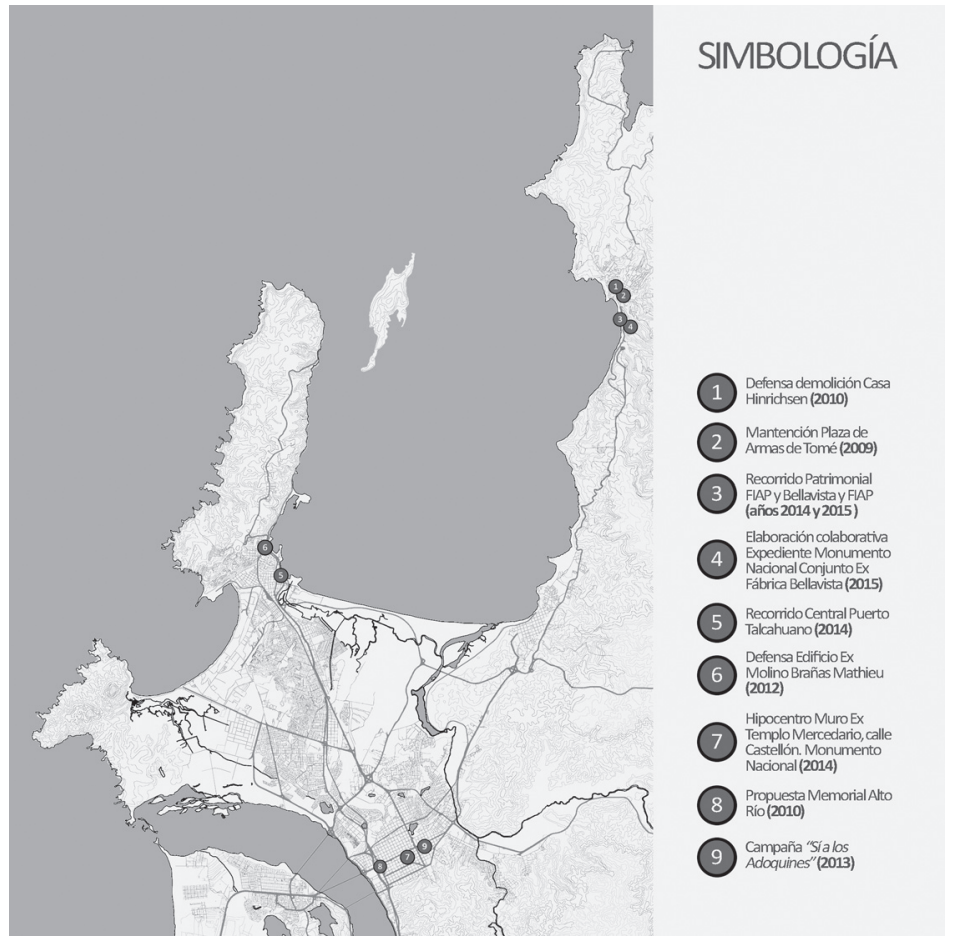

Fuente: Elaboración propia. 
A partir de la experiencia comparada se constata el rol que juega la identidad territorial en los procesos de resistencia, conflicto y desarrollo local que plantean las comunidades urbanas de la AMC en un escenario de metropolización homogeneizadora, que se profundiza con la catástrofe patrimonial que planteó el Terremoto y Tsunamis del 27 de Febrero de 2010. En ese marco se plantean diferentes tácticas y estrategias de activación patrimonial. Para agrupaciones locales como las de Tomé y Talcahuano, los días del patrimonio y las rutas patrimoniales configuran una apropiación táctica de un espacio dado por la institucionalidad. En efecto, dichos colectivos se constituyen en sujetos patrimoniales que ocupan un espacio institucionalizado por las incipientes políticas públicas patrimoniales para hacer acciones concretas de sensibilización sobre problemáticas concretas que van más allá de la educación patrimonial. Lo mismo ocurre con el apoyo a las declaratorias de Monumento Histórico, aun reconociendo las falencias de la Ley se ocupan desde una visión táctica que permite provisoriamente defender el patrimonio de su destrucción inmediata por el capital inmobiliario.

En el caso de Proyecta Memoria su sintonía con las nuevas tendencias de urbanismo emergente hace que no tenga barreras para innovar tanto en la forma como el contenido de su visión patrimonial centrada en la relación simbólica que establece cada comunidad con su patrimonio material, realizándose un aporte a pensar la interrelación entre el patrimonio intangible con el tangible a través de su metodología de abordaje del escombro como un ente simbólico. Se constituirían como "Plataforma de activación o entidad proyecto", según Hernández (2008:51-53), en tanto que "conciben el patrimonio en un sentido cultural u holístico en el marco de propuestas sociales concretas".

En segundo lugar, al analizar las nociones de patrimonio propuestas por cada organización emergen énfasis distintos. En los casos de Tomé y Talcahuano se plantea fuerte articulación entre el patrimonio e identidad territorial ("ser chorero", "ser tomecino") y el rescate de un patrimonio industrial que es testigo de una fase de desarrollo económica, social y cultural que marca la historia tanto de Talcahuano como Tomé y que se expresa en los recintos de El Molino Brañas Mathieu y de la Fábrica Bellavista Tomé. El énfasis en el rescate de un testimomio del patrimonio industrial no es menor. En efecto, El Molino al igual que la fábrica Bellavista Tomé son expresión viva del pasado económico del Concepción Metropolitano, que hizo que, entre la segunda mitad del siglo XIX y la primera del siglo XX, la región y sus principales localidades desarrollarán una identidad asociada a la industria triguera y textil, respectivamente. La noción de patrimonio es distinta en el caso de Proyecta Memoria de Concepción que pone énfasis no tanto en el rescate del patrimonio industrial y el patrimonio material asociado a una identidad territorial local como sí un foco en una metodología de (re) creación del patrimonio a partir de elaborar las memorias y experiencias asociadas a sus restos, a los escombros como entes simbólicos que expresan una experiencia de vida y una memoria colectiva asociada al patrimonio. Esa propuesta los va a llevar a intervenir con diferentes tipos de comunidades afectadas por desastres en su patrimonio desde los habitantes del contemporáneo edificio Alto Río a los habitantes de otras localidades como Arauco y de otras ciudades y regiones como Arica e Iquique.

Una de las características del urbanismo participativo que desarrollan las agrupaciones ciudadanas en Concepción tiene relación con la innovación en la activación patrimonial. En este marco destacan el desarrollo de rutas patrimoniales, intervenciones urbanas (Proyecta Memoria), jornadas de reflexión combinadas con recorridos diurnos y nocturnos, libros, manuales, manifiestos, archivos y exposiciones fotográfica, distinción a personajes ilustres. Particular énfasis en el 
trabajo comunitario y la reflexión sobre el patrimonio y sus instrumentos de protección aporta la experiencia de Tomé, y un enfoque más profundo de rescate histórico en Talcahuano, diferenciándose claramente el trabajo de Proyecta Memoria en base al urbanismo táctico.

En cuarto lugar, en relación al vínculo patrimonio y proyecto de desarrollo. Proyecta Memoria plantea una articulación a escala local, regional, nacional e internacional más amplia, en contraste con las experiencias de Tomé y Talcahuano donde prima un enfoque circunscrito a la comuna con mayor incidencia local en el caso del Consejo. Proyecta Memoria destaca también por proponer una visión crítica de los actuales procesos de "patrimonialización" en Chile, planteando que la Zona Típica como instrumento generalizado genera visibilidad pero puede estancar procesos de vitalización del patrimonio como espacio público de las comunidades.

Cabe señalar que cada organización aporta un elemento transformador a la noción de patrimonio existente La sensibilización y defensa del patrimonio cultural (Tomé), la mantención de la memoria urbana (Concepción)y la recuperación de los valores que reflejan su herencia cultural (Talcahuano) son su forma de resistir a las imposiciones del poder. Su crecimiento es inherente al desarrollo de la las redes sociales y la web.

En síntesis, una primera mirada a la experiencia de las agrupaciones patrimoniales del Gran Concepción nos permite plantear algunas pistas de hacia dónde va la praxis del patrimonio en la región, planteando la posibilidad de una articulación entre patrimonio y sustentabilidad, y patrimonio y derecho a la ciudad. Por un lado, su acción releva un elemento clave en el debate sobre la conservación del patrimonio actual que es su necesaria articulación con una visión más amplia del futuro de nuestras ciudades. Esta mirada prospectiva tiene que ver con la necesidad de que haya un proyecto de desarrollo compartido, y un compromiso de la comunidad con su patrimonio, lo que lleva al tema de la participación y al debate de las formas en que esta debe realizarse para la construcción de un patrimonio futuro que pueda heredarse a las nuevas generaciones. Por otro, su praxis de activación patrimonial nos enseña que proteger patrimonio significa proteger el legado del pasado pero también activar lugares y conocimientos que son útiles para el futuro de la ciudad (Capel, 2014). En particular al dar vida al patrimonio como espacio público las agrupaciones ciudadanas aportan a hacer posible el derecho a la ciudad desde una visión integral del patrimonio, que abarca no sólo lo tangible y material sino lo cultural y el entorno natural como un todo que merece ser apropiado por todos los ciudadanos y ciudadanas.

Como contrapunto a la apropiación del patrimonio por el mercado, es que emergen actores locales que rompen la visión estática sobre el patrimonio y encabezan procesos de gestión patrimonial que dan movimiento y dinamismo a un concepto que en sí no es estático constituyéndose en verdaderos "sujetos patrimoniales".

\section{Referencias bibliográficas}

AGRUPACIÓN MATTA SUR. Expediente para la Declaratoria de Zona Típica del Barrio Matta Sur. Santiago de Chile: Laboratorio Patrimonio Activo, Facultad de Arquitectura, Universidad de Chile, 2012. 
ALISTE, E.; ALMENDRAS, A. y CONTRERAS, M. La dinámica del territorio en la conurbación Concepción-Talcahuano: huellas urbanas para una interpretación de las transformaciones ambientales durante la segunda mitad del siglo XX. Revista de Geografía Norte Grande, 2012, № 52, 5-18.

ANDUEZA, P. La Política de Activación Patrimonial en Valparaíso: crítica y Propuestas. Ponencia presentada al Primer encuentro de la Sociedad de Políticas Públicas. Santiago de Chile, Universidad Adolfo Ibáñez, 2010. Disponible en Internet:

http://www.sociedadpoliticaspublicas.cl/archivos/MODULO_IV/PanelO6_Descentralizacion/Pablo_Andueza_La_politica_de_activacion_patrimonial_en_Valparaiso.pdf

APPADURAI, A. Airoots Interviews Arjun Appadurai (full version). 2008. Disponible en Internet: http://www.airoots.org/airoots-interviews-arjun-appadurai-full-version/

BORSDORF, A.; HIDALGO, R. \& SÁNCHEZ, R. A New Model of Urban Development in Latin America: The Gated Communities and Fenced Cities in the Metropolitan Areas of Santiago de Chile and Valparaíso. Cities, 2007, Vol. 5, N²4, p. 335-398.

CAIMANQUE, R. Regeneración Urbana y la Disputa por el espacio urbano: el caso de Valparaíso, Chile. En: ARICÓ, G.; MANSILLA, J. y LUCA, M. (editores). Mierda de Ciudad. Una rearticulación crítica del urbanismo neoliberal desde las Ciencias Sociales. Barcelona: POLEN Ediciones, 2015, p. 32-44.

CAPEL, H. El patrimonio: la construcción del pasado y del futuro. Barcelona: Ediciones del Serbal, 2014.

CARRIÓN, F. El laberinto de las centralidades históricas en América Latina. El centro histórico como objeto de deseo. Quito: Ministerio de Cultura del Ecuador, 2010.

CARRIÓN, F. Los centros históricos en la era digital en América Latina. En: REGUILLO, R. y GODOY, M. (editores). Ciudades translocales. Espacio, flujo, representación. Perspectivas desde Las Américas. México D.F.: ITESO, 2005a. p. 85-108.

CARRIÓN, F. El centro histórico como proyecto y objeto de deseo. EURE, 2005b, Vol. 31, № 93 p. 89-100.

CASTELLS, M. La era de la información: economía, sociedad y cultura. Vol. II El Poder de la Identidad. Madrid: Alianza, 2003.

CHOAY, F. Alegoría del Patrimonio. Barcelona: Gustavo Gili, 2007

COLLIN, C. La patrimonialización del espacio urbano como proceso conflictual. Ponencia presentada en el Seminario Interdisciplinario sobre Patrimonio: miradas cruzadas sobre el patrimonio: encuentros y desencuentros entre material e inmaterial. Santiago de Chile, Pontificia Universidad Católica de Chile, 2014. 
CONSEJO DE POBLADORES DE LA LEGUA. Expediente para la Declaratoria de Zona Típica de la Población La Legua. Santiago de Chile: FONDART Regional coordinado por C. Matus con apoyo de Laboratorio Patrimonio Activo Universidad de Chile, 2013.

CONSEJO COMUNAL PARA EL PATRIMONIO DE TOMÉ. Conclusiones Jornadas de Discusión Declaratoria de Monumento Histórico de Fábrica Bellavista Oveja Tomé. Tomé, octubre 2014.

DEACON, H. \& SMEETS, R. Authenticity, Value and Community Involvement in Heritage Management under the World Heritage and Intangible Heritage Conventions. Heritage \& Society, 2013, Vol. 6, No 2, p. 129-143.

DÉOM, C. \& THIFFAULT, M-A. Thoughts Towards a New Definition of Heritage, The Historic Environment, 2013, Vol. 4, No 1, p. 62-74.

DI SIENA, D. Urbanismo Emergente, Ciudadanía y Esfera Digital. Sevilla: Taller Hacking The City, 2012.

DUCCI, M. E. Las batallas urbanas de principios del tercer milenio. En: DE MATTOS, C.; DUCCI, M. E.; RODRÍGUEZ, A. y YÁÑEZ , G. (editores). Santiago en la globalización. ¿Una nueva ciudad?. Santiago de Chile: Ediciones Sur-Eure Libros, 2004, p. 137-166.

GARCÍA CANCLINI, N. Los usos sociales del Patrimonio Cultural. En: AGUILAR, E. Cuadernos Patrimonio Etnológico. Nuevas perspectivas de estudio. Sevilla: Junta de Andalucía, 1999, p. 16-33.

GARCÍA, F. Los claroscuros del patrimonio en Valparaíso. El Mercurio de Valparaíso, publicado el 10 de mayo de 2010. Disponible en Internet:

http://www.mercuriovalpo.cl/prontus4_noticias/site/artic/20100529/pags/20100529221044.html

GOBIERNO REGIONAL REGION METROPOLITANA DE SANTIAGO. Santiago 2021. Región Multicultural Estudio para el Fortalecimiento de la Identidad Regional. Santiago de Chile: GORE-SUBDERE, 2010.

GUERRERO, R.M. Patrimonio cultural mundial, territorio y construcción de ciudadanía. Construcción y apropiación social del patrimonio cultural de la ciudad de Valparaíso-Chile. Scripta Nova. Revista Electrónica de Geografía y Ciencias Sociales, 2012, Vol. XVI, No 388. Disponible en Internet: http://www.ub.es/geocrit/sn/sn-388.htm

GUERRERO, R.M. Los habitantes contra el patrimonio mundial: El rol de los habitantes en la gestión de áreas patrimoniales de las ciudades de México y Valparaíso. Apuntes, 2014, Vol. 27, № 2 , p. 92-103.

GUERRERO. M.J. Patrimonialización: Efectos en los Imaginarios Urbanos en tres Espacios Públicos de Valparaíso, Chile. Acta Científica XXIX Congreso de la Asociación Latinoamericana de Sociología, 2013, p. 1-9. 
HALL, S. ¿Quién necesita la 'identidad'?. En: HALL, S. y DU GAY, P. (editores). Cuestiones de Identidad. Buenos Aires: Amorrortu Editores, 2003, p. 13-39.

HARVEY, D. Heritage Pasts and Heritage Presents: Temporality, meaning and the scope of heritage studies. International Journal of Heritage Studies, 2001, Vol. 7, № 4, p. 319-338.

HERNÁNDEZ, J. Movimiento patrimonialista y construcción de la ciudad. En: FERNÁNDEZ, J.A. (coordinador). Ciudad e Historia: la temporalidad de un espacio construido y vivido. Madrid: Editorial AKAL y Universidad Internacional de Andalucía (UNIA), 2008. p. 39-60

HIDALGO, R. y JANOSCHKA, M. (editores). La Ciudad Neoliberal. Gentrificación y exclusión en Santiago de Chile, Buenos Aires, Ciudad de México y Madrid. Santiago de Chile/Madrid: Serie GEOlibos, Instituto de Geografía, Pontificia Universidad Católica de Chile; Departamento de Ciencia Política y Relaciones Internacionales, Universidad Autónoma de Madrid, 2014.

HIERNAUX, D. Los Imaginarios Urbanos: de la teoría y los aterrizajes en los estudios urbanos. EURE, 2007, Vol. XXXIII, Nº 99, p. 17-30.

INZULZA, J. y GALLEGUILLOS, X. Latino gentrificación y polarización: transformaciones socioespaciales en barrios pericentrales y periféricos de Santiago, Chile. Revista Geografía Norte Grande, 2014, No 58, p. 135-159.

LEFEBVRE, H. La producción del espacio. Madrid: Capt. Swing, 2014.

LÓPEZ, M.I \& VIDAL, C. Paisaje patrimonial y riesgo ambiental: Reocupación cultural y turística del espacio postminero en Lota, Chile. Revista de Geografía Norte Grande, 2012, N 52, p. 145-165.

LYDON, M. Urbanismo táctico 2 Acción a corto plazo / Cambio a largo plazo. New York: Nextgen, 2012.

ORTIZ, R. Mundialización y Cultura. Bogotá: Convenio Andrés Bello, 2004.

PAULSEN, A. Negocios inmobiliarios, cambio socioespacial y contestación ciudadana en Santiago Poniente. El caso del barrio Yungay: 2000-2013. En: HIDALGO, R. y JANOSCHKA, M. (editores). La Ciudad Neoliberal. Gentrificación y exclusión en Santiago de Chile, Buenos Aires, Ciudad de México y Madrid. Santiago de Chile/Madrid: Serie GEOlibos, Instituto de Geografía, Pontificia Universidad Católica de Chile; Departamento de Ciencia Política y Relaciones Internacionales, Universidad Autónoma de Madrid, 2014, p. XX

PRATS, L. Concepto y gestión del patrimonio local. Cuadernos de antropología social, 2005, Nº 21, p. 17-35.

SAGARIS, L. Citizens' Anti-highway Revolt in Post-Pinochet Chile: Catalyzing Innovation in Transport Planning. Planning Practice \& Research, 2014, Vol. 29, № 3, p. 268-286. 
SCARPACI, J.L. Plazas and Barrios: Heritage Tourism and Globalization in the Latin American Centro Histórico. Tucson: The University of Arizona Press, 2005.

SOSA, V. Planificación urbana y políticas de representación, el patrimonio como recurso de renovación urbana y espacio de confrontación en el casco histórico de Buenos Aires. Scripta Nova. Revista Electrónica de Geografía y Ciencias Sociales, 2010, Vol. XIV, № 331 (71). Disponible en Internet: http://www.ub.es/geocrit/sn/sn-331/sn-331-71.htm

STEFFENS, K. (editor). Urbanismo Táctico V3 Casos Latinoamericanos. Santiago de Chile: Ciudad Emergente + The Street Plans Collaborative, 2013.

TIRONI, M. Tecnologías democráticas: Repensando los movimientos sociales en el Chile actual. Revista Contenido. Arte, Cultura y Ciencias Sociales, 2014, N 4, p. 49-63.

UNESCO. Convención para la la Salvaguardia del Patrimonio Cultural Inmaterial. París: UNESCO, 2003.

YÚDICE, G. El recurso de la cultura: usos de la cultura en la era global. Barcelona: Editorial GEDISA, 2002. 